\title{
Tratamiento quirúrgico percutáneo del hallux valgus mediante osteotomías múltiples
}

\author{
M. de Prado ${ }^{a}$, P. L. Ripolla, J. Vaquerob y P. Golanóc \\ a Servicio de Traumatología y Cirugía Ortopédica. USP Hospital San Carlos. Murcia. \\ ' Servicio de Traumatología y Cirugía Ortopédica. Hospital General Universitario Gregorio Marañón. Madrid. \\ 'Departamento de Ciencias Morfológicas. Universidad de Barcelona.
}

Objetivo. Se presenta la experiencia del tratamiento del hallux valgus mediante la realización de osteotomía distal del primer metatarsiano y osteotomía de la falange con liberación del abductor por técnicas percutáneas.

Material y método. Desde junio de 1996 hasta junio de 1997 han sido intervenidos 64 pacientes, la mayor parte mujeres con hallux valgus de grado moderado con un ángulo intermetatarsiano medio de $14,5^{\circ}$ y un ángulo del complejo articular proximal (PASA) de $17,7^{\circ}$ de media.

Resultados. Los resultados obtenidos desde el punto de vista radiológico pusieron de manifiesto una corrección media de $5^{\circ}$ del ángulo intermetatarsal y se obtiene un valor medio del PASA de $8,2^{\circ}$. La consolidación de las osteotomías se consiguió en el $100 \%$ de los pies sin retardos de consolidación significativos, salvo en un caso que precisó más de tres meses. Por lo que se refiere a las complicaciones, al no utilizar ningún medio de fijación, el desplazamiento de las osteotomías fue muy frecuente, pero sólo en un $8 \%$ de la serie tuvieron repercusión clínica. El acortamiento del primer metarsiano fue la norma alcanzando como media $0,7 \mathrm{~cm}$, lo que se intentó compensar con un descenso de la cabeza del primer metatarsiano; la metatarsalgia por trasferencia en esta serie ocurrió en el $25 \%$ de los casos. No se presentaron alteraciones neurológicas, infección ni síndromes flebíticos postquirúrgicos.

Conclusión. Parece que la técnica de Reverdin-Isham, por vía percutánea, es un buen método para el tratamiento del hallux valgus, ya que proporciona unos resultados clínicos muy aceptables, sin presentar complicaciones importantes; en el momento actual hay que asociar con mucha más frecuencia la realineación metatarsal a la cirugía del hallux valgus para evitar las metatarsalgias por trasferencia.

Palabras clave: hallux valgus, osteotomías percutáneas.

\footnotetext{
Correspondencia:

M. de Prado.

USP Hospital de San Carlos.

Miguel Hernández, 12.

30011 Murcia.
}

Recibido: septiembre de 2002.

Aceptado: marzo de 2003.

\section{Percutaneous hallux valgus repair by multiple osteotomies}

Objective. Our experience with the treatment of hallux valgus by distal first metatarsal osteotomy and phalanx osteotomy with abductor release using percutaneous techniques is presented.

Materials and methods. From June 1996 to June 1997, 64 patients underwent surgery. Most were women with moderate-grade hallux valgus and a mean intermetatarsal angle of $14.5^{\circ}$ and a mean proximal articular sect angle (PASA) of $17.7^{\circ}$.

Results. Radiology disclosed a mean correction of $5^{\circ}$ in the intermetatarsal angle and $8.2^{\circ}$ in the PASA. The osteotomies consolidated in all feet without significant delays, except for one case that required more than three months. Complications were frequent due to the absence of fixation. Osteotomies often slipped, but there were clinical repercussions in only $8 \%$ of the series. The first metatarsal was generally shortened by the procedure, reaching a mean of $0.7 \mathrm{~cm}$, which was compensated for by lowering the head of the first metatarsal. Transfer metatarsalgia occurred in $25 \%$ of cases. No postoperative neurological injuries, infection or phlebitic syndromes occurred.

Conclusion. The percutaneous Reverdin-Isham technique seems to be a good method for hallux valgus repair because it provides acceptable clinical results without important complications. At present, metatarsal realignment must often be associated to hallux valgus surgery to prevent transfer metatarsalgia.

Key words: hallux valgus, percutaneous osteotomy.

El objetivo del tratamiento quirúrgico del hallux valgus es corregir todos los elementos patológicos de la enfermedad, así como mantener el antepié biomecánicamente funcional; si queremos ser eficaces en la resolución de las diferentes deformidades presentes, precisaremos de múltiples gestos quirúrgicos que exigirán amplias vías de abordaje siguiendo los postulados de la cirugía tradicional. La cirugía 
ortopédica moderna tiende de un modo evidente a la utilización de técnicas poco invasivas o percutáneas que resuelvan o minimicen algunos de los problemas planteados en la cirugía abierta, disminuyendo las posibles complicaciones y mejorando y acortando el proceso de recuperación postquirúrgica $^{1,2}$.

Salvo en aquellos casos en los que el estado de la articulación metatarsofalángica del primer dedo presente signos de artrosis tan evolucionados que harían inviable su función obligando a aplicar técnicas de resección-artroplastia o artrodesis, consideramos que el tratamiento adecuado sería la práctica de múltiples osteotomías correctoras que restituyeran la estructura del metatarsiano y de la falange proximal, y no sólo su posición ${ }^{3-7}$. Estas osteotomías se verán acompañadas de gestos quirúrgicos sobre las partes blandas que completarían la obtención de resultados óptimos. En este artículo presentamos nuestra experiencia en el tratamiento quirúrgico percutáneo del hallux valgus mediante osteotomías múltiples.

\section{MATERIAL Y MÉTODO}

Desde junio de 1996 hasta junio de 1997 han sido intervenidos, siempre por el mismo cirujano, 64 pacientes mediante la técnica percutánea que se describirá a continuación, siendo 62 de ellos mujeres (97\%) y 2 hombres (3\%). La serie se compone de 35 pies derechos y 29 izquierdos. La edad media fue de 51 años, con una máxima de 79 y una mínima de 18; a destacar que se han intervenido 37 pacientes mayores de 50 años, lo que supone un $58 \%$ del total.

\section{Técnica quirúrgica}

Todos los pacientes incluidos en esta serie han sido intervenidos mediante anestesia local por bloqueo nervioso realizado a la altura del tobillo. Utilizamos una solución anestésica con el $50 \%$ de bupivacaína al $0,75 \%$ y el otro $50 \%$ de mepivacaína al $2 \%$; habitualmente se utilizan 15 centímetros cúbicos de esa solución para obtener un bloqueo completo del pie. Una vez obtenida la anestesia del pie y tras la preparación del campo quirúrgico siguiendo las normas generales de asepsia para cualquier cirugía tradicional, se ha realizado en todos los casos de esta serie la siguiente técnica (figs. 1 y 2).

1. Exostosectomía. Por una incisión de 0,5 a 1 centímetro, situada en la cara interna y plantar del primer metatarsiano, justo por detrás y encima del sesamoideo medial profundizamos la incisión con un solo corte hasta alojar el bisturí en el interior de la cápsula articular de la articulación metatarsofalángica del primer dedo, quedando alojado el bisturí sobre la exóstosis; con un movimiento oscilante despegamos toda la cápsula del hueso en su porción medial. Posteriormente, con una raspa pequeña completaremos el despegue de la cápsula y raspamos los tejidos fibrosos que quedan sobre la exóstosis.

A continuación introducimos por la vía realizada la broca tipo Shannon larga con la que iniciaremos el proceso de rebajar el volu-

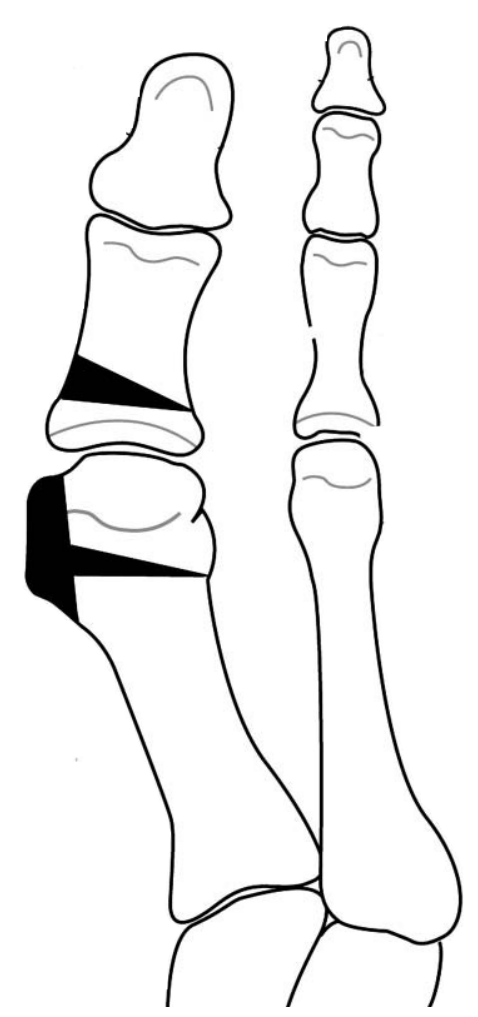

Figura 1. Diseño de la exostosectomía y de las osteotomías (visión dorsoplantar).

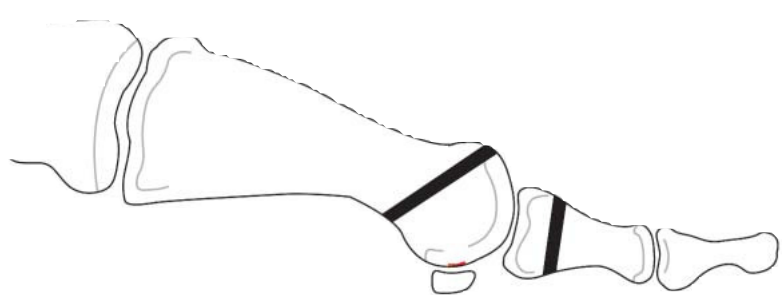

Figura 2. Diseño de las osteotomías (visión lateral).

men de la exóstosis y así crear un espacio para poder introducir la fresa de 4,1 mm con la que completaremos la eliminación de la exostosectomía. Tras cada aplicación de la broca a velocidades de aproximadamente, 2.000 a 6.000 revoluciones por minuto para no producir necrosis ósea y realizando una leve presión sobre la zona de la exóstosis, saldrá todo el material óseo en forma de «papilla» debiendo completar su eliminación con las raspas insistiendo en la extracción de aquellas esquirlas o restos óseos que quedan adheridos a la cápsula y que controlaremos con el fluoroscopio. Repitiendo este proceso alcanzaremos la exostosectomía deseada que nos indicará el paso al siguiente gesto quirúrgico.

2. Osteotomía distal del primer metatarsiano. Hemos seguido la técnica descrita por Isham al modificar la osteotomía de Reverdin. Por la misma vía de acceso que hemos utilizado para la exostosectomía, introduciremos de nuevo la broca Shannon 44 larga que colocaremos sobre la cara interna del metatarsiano, en una dirección oblicua de aproximadamente $45^{\circ}$, teniendo como límite 
en la cortical superior la superficie del cartílago articular de la cabeza del metatarsiano y como límite en la cortical inferior la localización inmediatamente posterior a la posición de los sesamoideos; en esta posición de la línea de osteotomía de distal dorsal a plantar proximal, se inicia el corte que se prolonga hasta la cortical exterior, que respetamos en unos milímetros, y procedemos a eliminar más cantidad de la cortical media para así fabricar la cuña que deseamos extraer. A continuación, con un movimiento de varización del primer dedo, realizamos la osteoclasia de la cortical lateral del primer metatarsiano, cerrándose así la cuña, y quedando más estable que si hubiéramos completado la osteotomía en todo el metatarsiano con la fresa de corte.

3. Tenotomía del abductor del hallux y capsulotomía lateral metatarsofalángica. Una vez finalizados los tiempos a nivel de la cabeza del primer metatarsiano, realizamos una nueva vía a nivel de la cara dorsal y lateral de la articulación metatarsofalángica del primer dedo, introduciendo una hoja de bisturí Beaver 64 en posición paralela al primer dedo, y alojándola sobre la cara interna de la base de la falange. Realizando un giro de $90^{\circ}$ hacia externo y movilizando en varo el dedo sentiremos el corte de la inserción del abductor hasta completarlo totalmente, y realizando una capsulotomía incompleta para no desarticular excesivamente la articulación.

4. Osteotomía de la base de la primera falange del primer dedo tipo Akin ${ }^{1}$. Tras realizar el tiempo sobre las partes blandas, con el bisturí haremos una nueva incisión de 0,3 a 0,5 centímetros en la cara dorsal de la base de la primera falange del hallux, inmediatamente por dentro de los tendones extensores, y llegamos hasta el periostio; con la raspa pequeña desperiostizamos toda la cara interna de la base de la falange, donde colocaremos posteriormente la fresa de corte lateral para realizar la osteotomía de cuña interna, respetando la parte de la cortical interna, que terminaremos de romper por osteoclasia.

5. Vendaje. Una vez finalizada la cirugía, debemos colocar un vendaje que será de vital importancia para mantener la corrección obtenida con la intervención, al no realizar osteosíntesis. Se utilizan 4 gasas de $3 \times 3$, extendidas en su totalidad y, colocadas unas sobre otras, las doblamos por la mitad; se colocarán entre el primer y segundo dedo, cruzándolas sobre la cara interna de la exostosectomía y haciendo una leve tracción hipercorregiremos el dedo con ligera inclinación hacia plantar; cubrimos el resto del antepié con tres gasas abiertas en su totalidad de 3 x 3 , y con una venda de gasa completaremos el vendaje, en el cual incluiremos el antepié y el primer dedo. Posteriormente utilizaremos unas cinchas cruzadas de esparadrapo (taping) en la misma dirección de las primeras gasas colocadas para reforzar la solidez del vendaje, que como hemos indicado se deja en ligera hipercorrección. Se cubre todo el antepié con una gasa de tubo que es fijada con esparadrapo a la piel para evitar que se desplace en los días posteriores a la intervención.

Pasados 8 días se realiza la primera revisión en la que retiraremos el vendaje colocado en la sala operatoria y los puntos de sutura; posteriormente colocaremos un vendaje mucho más simple, que puede ser cambiado diariamente por el paciente, y que consiste en la colocación de un separador interdigital de un material semirrígido y una cincha metatarsal con venda elástica autoadhesiva sobre sí misma, tipo Coban ${ }^{\circledR}$ (3-M). Este vendaje deberá ser mantenido durante las 24 horas del día las 3 o 4 semanas siguientes a la cirugía, para después ser mantenido solamente durante el día y retirado para el reposo en cama, durante las siguientes 2 o 3 semanas. Durante las primeras 3 o 4 semanas, el paciente caminará con un zapato especial postquirúrgico, con suela rígida para ayudar a mantener la estabilidad de la osteosíntesis.

Las indicaciones de esta técnica con los 4 gestos expuestos estarán reservadas para los hallux valgus sin artrosis o con una artrosis leve a moderada con un ángulo metatarsofalángico (MF) incluso superior a los $40^{\circ}$, con un ángulo del complejo articular proximal (PASA) aumentado y con un ángulo intermetatarsiano (IM) no superior a $\operatorname{los} 18^{\circ}$.

\section{Cirugía asociada}

La intervención de hallux valgus ha sido asociada en 20 casos $(31 \%)$ a tenotomías de tendones flexores y extensores más osteotomía de las falanges proximal y media del segundo dedo como tratamiento de su deformidad en martillo. En 11 ocasiones (18\%) se han intervenido el segundo, tercer y cuarto dedo en martillo. En total, los casos en que se precisó cirugía sobre los dedos menores a la vez que la de hallux valgus fue de 31 casos (49\%).

Simultáneamente a la cirugía de hallux valgus, se han realizado osteotomías de las metáfisis distales del segundo metatarsiano en 7 casos $(11 \%)$, y del segundo, tercero y cuarto en $12(19 \%)$ ya que presentaban problemas de metatarsalgias preoperatorias evidentes, incluyendo en total al $30 \%$ de los pacientes (fig. 3).

\section{Valoración clínica}

La forma del antepié ha sido claramente dominada por el «pie egipcio» en 55 pies $(85 \%)$, siendo las formas «griego» y «cuadrado» en 7 y 2 pies (12\% y $3 \%$ respectivamente). El antepié se ha encontrado en posición de pronado en el $50 \%$ de los casos (32 pies), no apareciendo en ninguno la posición de supinado y presentando el otro $50 \%$ de los pies la posición de neutro. No existió equino en ningún caso de la serie. Por lo que respecta al retropié, fue neutro en 36 pies $(56 \%)$ y valgo en los restantes 28 (44\%).

La bursitis sobre la exóstosis del primer metatarsiano se encontraba presente en todos los casos (100\%), estando sólo en 2 de ellos abierta. El dolor estuvo presente también en todos los pacientes de la serie, siendo calificado de leve en 6 casos $(9 \%)$, moderado en $52(82 \%)$, e incapacitante en otros 6 casos $(9 \%)$.

La movilidad de la articulación metatarsofalángica del primer dedo se encontraba afectada en 37 pacientes, es decir, en el $58 \%$ de la serie; de éstos se encontraba levemente limitada en 30 casos, moderadamente limitada en 6 , y no existía prácticamente movimiento (hallux rigidus) en 1 caso.

En 34 pies (54\%) se presentaron deformidades asociadas de los dedos menores, estando afectado solamente el segundo dedo en 23 casos, y más dedos en 11 pacientes. El $46 \%$ de los pies no tenía deformidades significativas en los dedos menores. La metatarsalgia es otra de las variables recogidas en la valoración clínica, encontrándose presente en el $32 \%$ de los casos (22 pies), de los que 8 afectan sólo al 

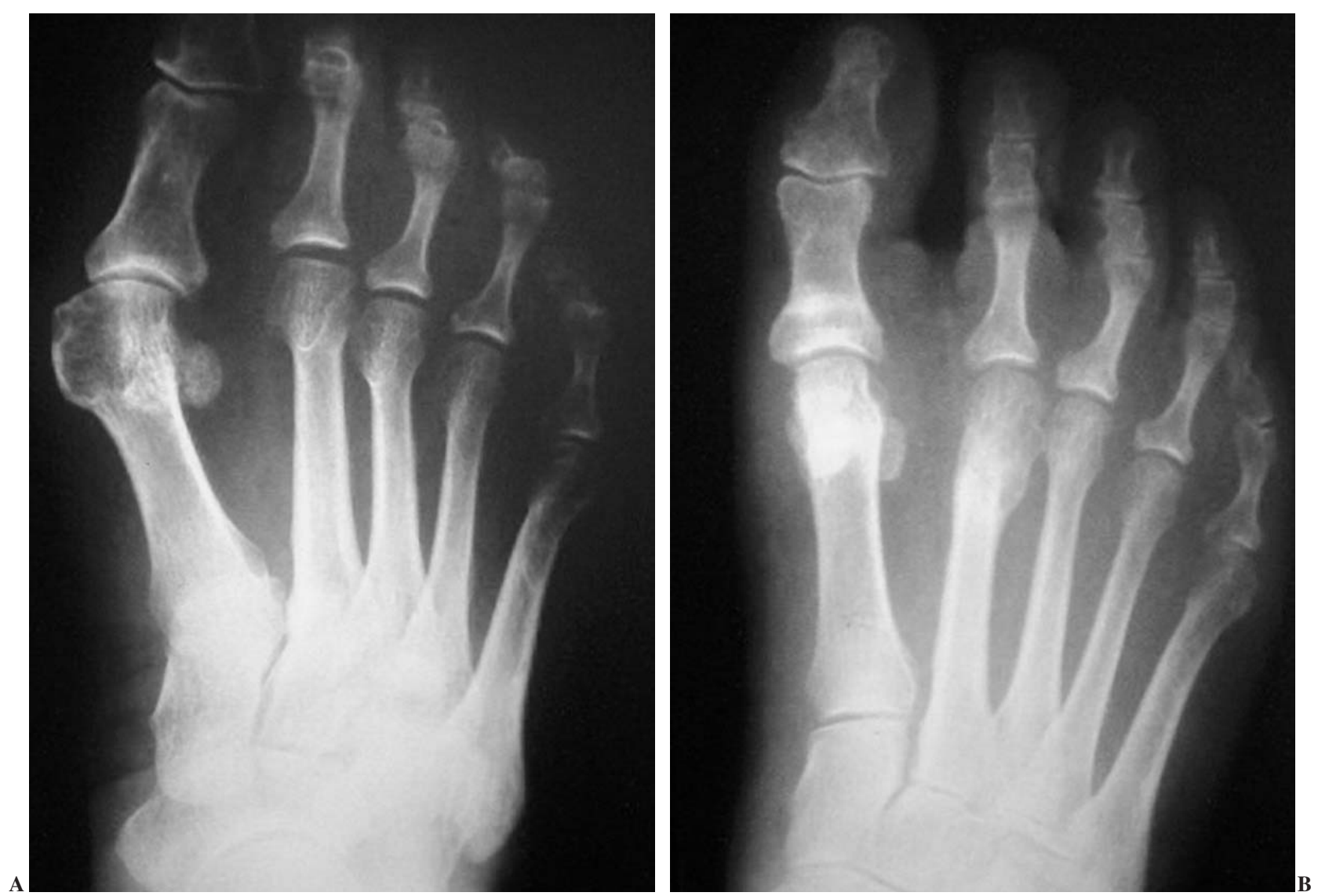

Figura 3. Caso 2. A: radiografía preoperatoria de hallux valgus. B: radiografía postoperatoria; nótese que también se realizó una osteotomía del segundo metatarsiano (resultado satisfactorio).

segundo radio, y 14 al segundo, tercer y cuarto metatarsianos. No presentaban alteraciones en el apoyo de las cabezas metatarsianas preoperatoriamente 42 pies, es decir, un $66 \%$.

Otro de los motivos que hace consultar al paciente y que fue valorado es el tipo de calzado que utiliza como consecuencia de su patología en los pies, encontrándonos que llevaban un calzado normal el $37 \%$ de los pacientes (24 casos), debiendo hacer modificaciones en el calzado normal para poder llevarlo sin problemas 29 pacientes, y viéndose obligados a utilizar un zapato ortopédico en 11 casos. Por tanto, los pacientes que utilizaban alguna modificación en el calzado alcanzó el $63 \%$ de la serie. El $90 \%$ de los casos fueron hallux valgus de origen biomecánico, siendo solamente 4 de ellos del tipo etiopatogénico juvenil y 2 casos recidivas de técnicas anteriores en las que sólo se trataron las partes blandas.

\section{Evaluación radiológica}

El grado de metatarsus varus ha sido determinado por el ángulo IM, es decir, el ángulo formado por los ejes del primer y segundo metatarsiano, habiéndose presentado con una divergencia de menos de $10^{\circ}$ en 2 pies, entre 10 y $15^{\circ}$ en 38 pies y entre 15 y $20^{\circ}$ en los 24 restantes de la serie; siendo la media preoperatoria de $14^{\circ}, 4$, con un máximo de $20^{\circ}$ y mínimo de $10^{\circ}$.

El grado de valgo del primer dedo, que viene determinado por la medida del ángulo MF, fue inferior a $20^{\circ}$ en 4 casos; comprendido entre 20 y $30^{\circ}$ en 20 pies, entre 30 y $40^{\circ}$ en 29 casos y más de $40^{\circ}$ en 11 de los pies de la serie. La media del ángulo metatarsofalángico ha sido de $34^{\circ}$, con un máximo de $56^{\circ}$ y un mínimo de $20^{\circ}$.

La posición de la superficie articular de la cabeza del primer metatarsiano se ha obtenido mediante la determinación del ángulo del complejo articular proximal (proximal articular sect angle o PASA), habiéndose encontrado un máximo de $36^{\circ}$, un mínimo de $10^{\circ}$, y una media de $17,7^{\circ}$. Ninguno de los pacientes de la serie presentaba menos de 8 ; $16^{\circ}$ el número de casos fue de 30 (47\%), y con más de $16^{\circ}$ encontramos 34 casos (53\%).

La morfología de la cabeza se presentó de forma redondeada en 60 casos (94\%), cuadrada en 2 y con la presencia de cresta en otras 2 ocasiones. La existencia de artrosis en la misma la hemos clasificado en 4 grupos, siendo ausente en 23 casos, leve en 30, moderada en 10 e intensa en 1 caso; es decir, que el $83 \%$ presenta una artrosis ausente o leve. 
La longitud funcional del primer metatarsiano ha sido la misma que la del segundo, es decir, una fórmula metatarsal plus minus, en 27 de los casos, ha sido menor (index minus) en 32 y mayor en 5; por lo que las fórmulas index minus e index plus minus suponen el $92 \%$ de la serie; la longitud máxima del primer metatarsiano fue de 7,9 centímetros, con una mínima de 5,3 y una media de 6,3 centímetros.

La posición de los sesamoideos se ha encontrado alterada en prácticamente la totalidad de la serie, encontrándose en posición I, 2 casos; posición II, 8 casos; posición III, 19 casos; posición IV, 30 casos; y posición V, en 5 casos. El porcentaje de las posiciones III, IV y V, que son evidentemente patológicas, supone el $84 \%$ de la serie.

\section{RESULTADOS}

Los 64 pacientes han sido revisados con un seguimiento mínimo de 24 meses y máximo de 37, por un mismo examinador, con un tiempo medio de la revisión de 30,2 meses. Además del cuidadoso examen clínico que se ha practicado a los pacientes, se realizó un estudio radiológico de frente y de perfil en carga a todos ellos.

\section{Clínicos}

La bursitis ha desaparecido en el $100 \%$ de los casos intervenidos, habiendo podido utilizar un zapato normal, sin precisar modificaciones debidas al hallux valgus el $98 \%$ de los casos. Algunos pacientes que utilizan plantillas de descarga para el tratamiento de la metatarsalgia, bien residual o preexistente, han señalado que precisan utilizar calzados de mayor tamaño para poder acomodar las plantillas. La movilidad tras la intervención se ha encontrado dentro de un arco de normalidad en el $67 \%$ de los casos, y limitaciones a la misma en el $33 \%$ restante.

El dolor a nivel del primer radio lo hemos encontrado tras el tratamiento quirúrgico en el $25 \%$ de los casos (16 pies), y ha sido relacionado fundamentalmente con la marcha prolongada y con los cambios estacionales, no existiendo ningún caso de persistencia de dolor incapacitante o de carácter moderado. El 75\% de los casos operados no referían ningún dolor a ese nivel (primer radio).

La estabilidad clínica, que podemos percibir mediante el intento suave de desplazamiento del foco de osteotomía sin que lo consigamos, ni tengamos la sensación de roce en las superficies óseas osteotomizadas, se ha obtenido en un tiempo medio de 27,2 días (rango de 21 a 40), habiéndose conseguido en menos de 1 mes en el $87 \%$ de los casos (fig. 4).
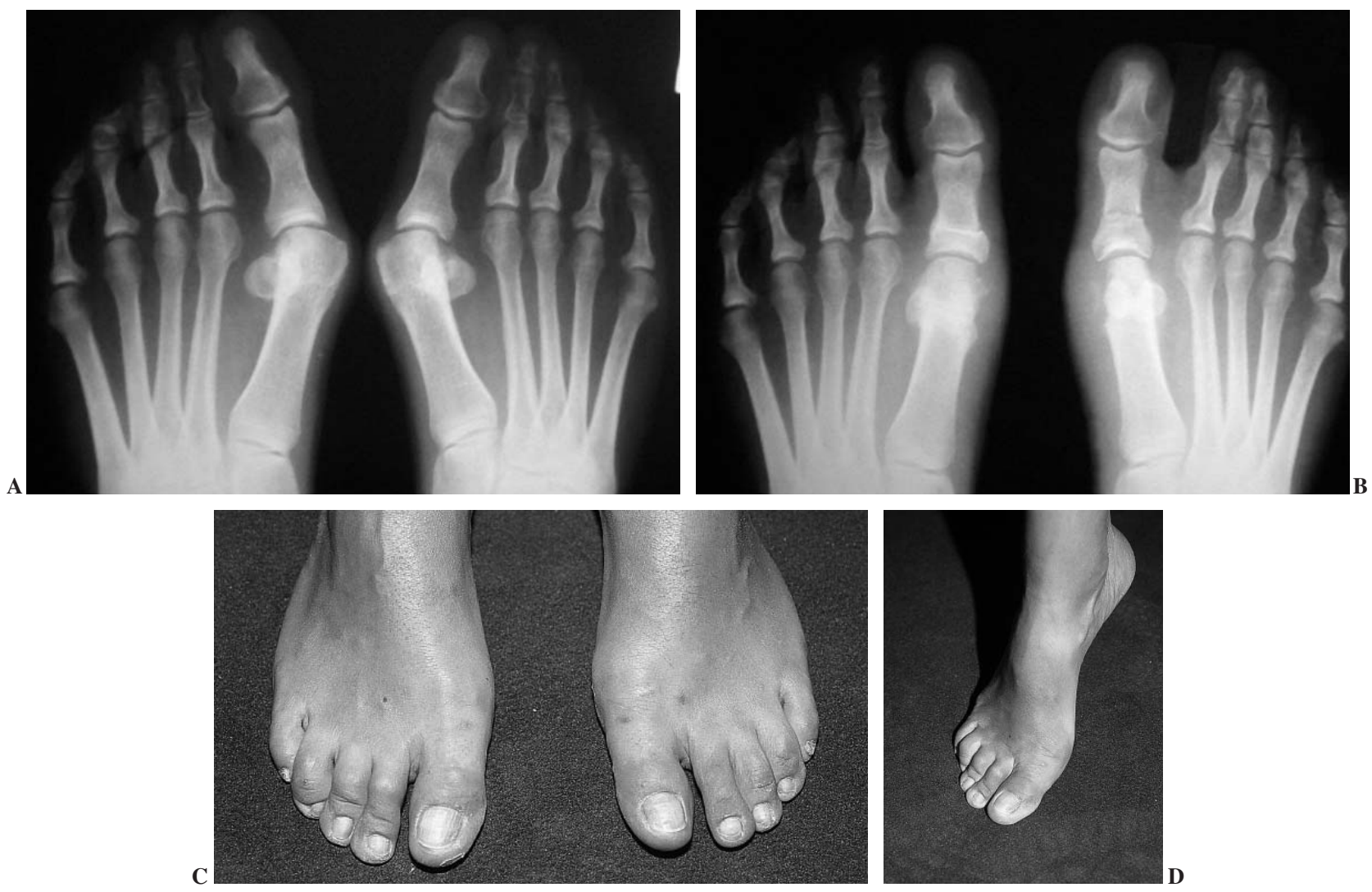

Figura 4. Caso 1. A: radiografía preoperatoria de un hallux valgus bilateral. B: radiografía postoperatoria. C: resultado clínico. D: resultado funcional (ambos fueron satisfactorios). 


\section{Radiológicos}

La corrección del ángulo MF (valgo del primer dedo) se ha reducido de un modo muy eficaz, quedando incluidos entre los extremos de $0^{\circ}$ a $20^{\circ}, 62$ casos $(96 \%)$, y sólo superando los $20^{\circ}$ de deformidad, 2 casos (4\%); en ningún caso se produjo un hallux varus residual, y la media postoperatoria del ángulo MF ha sido de $10^{\circ}$, con una corrección media de $24^{\circ}$ (rango de $6^{\circ}$ a $45^{\circ}$ ).

El ángulo IM ha sido corregido de media $5^{\circ}$. Del total de la serie, 48 casos han quedado incluidos entre los márgenes de 0 a $10^{\circ}$, por tanto el $75 \%$ se encuentra entre los márgenes de normalidad o leve alteración; y entre los 10 y los $15^{\circ}$ han persistido 16 casos $(25 \%)$, teniendo un rango de máxima corrección de $10^{\circ}$ y un mínimo de $0^{\circ}$.

La corrección de la posición de la carilla articular con respecto a la diáfisis metatarsal, que viene determinada por el PASA, ha quedado en la serie tras la intervención con un valor medio de $8,2^{\circ}$, con un máximo de $22^{\circ}$ y un mínimo de $0^{\circ}$; la corrección media obtenida fue de $9,5^{\circ}$ con un rango entre $0^{\circ}$ y $24^{\circ}$; resultando con menos de $8^{\circ}$ de PASA el $55 \%$ de los pacientes ( 35 casos), entre 8 y $16^{\circ}$ el $42 \%$ (27 casos) y con más de $16^{\circ}$ sólo 2 pacientes (3\%).

La longitud del primer metatarsiano ha disminuido de un modo significativo en toda la serie, habiendo tenido un acortamiento medio de 0,7 centímetros, con un máximo de 1,2 y un mínimo de 0,1 centímetros, como en un caso, en el que se produjo un desplazamiento lateral externo distal de la osteotomía y presentó una consolidación con callo hipertrófico. Como consecuencia de este acortamiento del primer radio se ha producido una modificación en la fórmula metatarsal, quedando incluida en la fórmula index minus el $86 \%$ de los pacientes, index plus minus el $6 \%$, y la fórmula index plus en el $8 \%$ de los casos.

El recentraje de los sesamoideos se ha obtenido parcialmente, quedando la posición de los mismos como puede apreciarse en los siguientes resultados: grupo I, 9 casos; grupo II, 31 casos; grupo III, 17 casos; grupo IV, 7 casos y grupo V, 0 casos. Así, la proporción de casos patológicos, entre los que se incluyen los grupos III, IV y V, queda con el 38\% de los casos.

La consolidación de las osteotomías se consiguió en una media de 69,5 días (rango 57 a 91), produciéndose en menos de 2 meses en el $26 \%$ de los casos (17 pies); entre 2 y 3 meses, en el $72 \%$ de los casos (46 pies) y solamente 1 caso precisó de más de 3 meses para la consolidación.

\section{Complicaciones}

La movilización de la osteotomía ha sido la complicación más frecuente al haberse detectado en el $42 \%$ de los casos cuando comparamos los estudios radiológicos realizados a la semana de la intervención y al mes de la misma en que ya existe una buena estabilidad fibrosa. El despla- zamiento de esta osteotomía de un modo significativo, es decir superior a $2 \mathrm{~mm}$, ocurrió solamente en 5 casos ( $8 \%$ de la serie), habiendo consolidado todos ellos correctamente en los tiempos biológicos adecuados. Señalaremos que 16 casos $(25 \%)$ han presentado metatarsalgia por transferencia al segundo o tercer metatarsiano, de los cuales en 2 ocasiones se han producido fracturas por estrés en la diáfisis del segundo metatarsiano. A pesar de la movilización inmediata de los pacientes, se encontró en 1 caso la aparición de una flebitis, que cedió al tratamiento habitual sin producirse en ningún caso trombosis venosa. Las alteraciones de la sensibilidad por afectación de las ramas cutáneas dorsales lesionadas por la puerta de entrada o bien al utilizar los instrumentos motorizados, se produjeron en 4 casos (7\%). Hay que destacar que las alteraciones sensitivas en el primer dedo en las revisiones inmediatas postoperatorias llegan a alcanzar el $30 \%$ de los pies y que, con el paso del tiempo son recuperadas, quedando, como hemos dicho, como una disestesia sólo en el $7 \%$ de los casos. Como incidencia peroperatoria señalaremos la rotura de fresas de corte en 2 casos (3\%), que fueron extraídas sin dificultad con la utilización del fluoroscopio.

\section{Resultados globales}

Los resultados postoperatorios globales han sido valorados siguiendo los criterios de evaluación de Groulier et $\mathrm{al}^{2}$, ligeramente modificados para adaptarlos a las técnicas de cirugía percutánea, y que se establecen en tres apartados:

1. Los resultados a nivel del primer radio se han obtenido evaluando la deformidad en valgo postoperatorio, la desaparición del dolor y la movilidad residual en la articulación metatarsofalángica.

2. Los resultados sobre el estado del antepié han sido evaluados por la influencia de la intervención en la metatarsalgia residual y el ángulo IM existente.

3. La actividad funcional del paciente ha sido juzgada por la facilidad para utilizar calzado y por el grado de actividad que recupera.

Los resultados obtenidos de la aplicación de los criterios de Groulier nos han dado los siguientes resultados globales: 37 casos con un muy buen resultado (58\% de la serie), 14 casos con un buen resultado (22\%), 11 pies con un resultado considerado pasable (17\%) y 2 casos de mal resultado (3\%). Es decir $80 \%$ de muy buenos y buenos resultados según la valoración del cirujano.

La apreciación subjetiva del paciente también ha sido recogida ajustándose a los 4 mismos apartados, obteniendo una valoración del resultado de la intervención, por parte de los pacientes, como sigue: muy buena, 42 casos (66\%); buena, 16 casos (24\%); pasable, 4 casos (7\%) y mala, 2 casos (3\%). El $90 \%$ de muy buenos o buenos resultados, y el 10\% de pasables o malos resultados. 


\section{DISCUSIÓN}

Con respecto a la técnica, el primer dato que debemos destacar tras el análisis de los resultados es la posibilidad efectiva de realizar osteotomías, tanto a nivel del primer metatarsiano como en la base de la falange, por técnicas percutáneas, como habían promulgado Isham y White, obteniendo resultados globales superponibles o superiores en algunos aspectos a las técnicas de osteotomía tradicionales abiertas $^{3-7}$.

El tiempo de consolidación de las osteotomías realizadas por técnicas percutáneas puede ser considerado del todo fisiológico, e incluso han sido obtenidos más rápidamente que con las técnicas tradicionales (abiertas) u otras técnicas percutáneas más agresivas ${ }^{8}$. Consideramos que este comportamiento se debe a dos causas fundamentalmente: la mínima lesión vascular y de los tejidos circundantes producida en la técnica percutánea, como hemos podido comprobar en los estudios anatómicos realizados por nosotros, y en segundo lugar la presencia de detritus óseo («papilla ósea») en el foco de osteotomía producido tras la utilización de las fresas de corte y rebajado de la exóstosis, que se comporta como un auténtico injerto óseo autólogo (aporte biológico de primera calidad) estimulando la consolidación del foco de osteotomía.

El dilema entre fijación-no fijación de las osteotomías en el tratamiento quirúrgico del hallux valgus ha sido una constante en la cirugía del pie. Existe una tendencia generalizada a creer que la fijación asegura un buen resultado ${ }^{9}$ al mantener, mediante la osteosíntesis, las correcciones deseadas. En realidad, salvo las técnicas a compresión AO, que no suelen ser utilizadas de forma generalizada en cirugía del pie, el resto de métodos de fijación (agujas de Kirschner, pins metálicos, suturas de acero, etc.) evitarán solamente grandes desplazamientos, nunca pequeñas modificaciones de la posición que es lo que suele suceder cuando dejamos sin fijar las osteotomías; por el contrario, la utilización de métodos de estabilización producirá los inconvenientes propios de los materiales de osteosíntesis (migración, infección percutánea, etc.). En nuestra casuística no hemos utilizado ningún medio de síntesis para la fijación de las osteotomías, y hemos obtenido unos resultados absolutamente superponibles a los de Funk y Wells ${ }^{10}$ en 1972 y McClamry ${ }^{11}$, que realizaron las osteotomías de Reverdin sin fijación, con el 94\% de buenos resultados; así como también son superponibles a las series de $\mathrm{Wu}^{12,13}$, que utilizan métodos de síntesis para las osteotomías en chevron.

Uno de los factores que limitaba la indicación de las osteotomías distales del primer metatarsiano como tratamiento quirúrgico del hallux valgus era la edad, y clásicamente se aceptaba que en los pacientes mayores de 50 años no se debían utilizar estas técnicas ${ }^{14}$. En nuestra serie, el 58\% de los casos intervenidos quirúrgicamente presentaban, en el momento de la operación, una edad superior a los 50 años, y no se ha podido comprobar ninguna variación en cuanto a los resultados obtenidos en comparación con los pacientes menores de 50 años (42\%), coincidiendo nuestra casuística con la de Tollison y Baxter ${ }^{15}$. Por tanto discrepamos, junto a ellos, en la recomendación actual de no indicar osteotomías en el tratamiento quirúrgico del hallux valgus en pacientes mayores de 50 años.

Con respecto a los resultados clínicos, la limitación de la movilidad articular de la articulación metatarsofalángica en las técnicas tradicionales es una complicación frecuente, pero que no ha podido ser valorada ni comunicada con parámetros precisos, posiblemente por la dificultad existente para establecer técnicas de medición reproducibles ${ }^{16}$. La rigidez articular secundaria a la cirugía abierta del hallux valgus es posiblemente producida por: a) adherencias intraarticulares, tanto de la cápsula, como de los sesamoideos; b) excesiva disección y posterior cicatrización de las estructuras periarticulares, y c) excesiva tensión y plicatura de la sutura de la cápsula medial practicada. Ninguna de estas tres premisas, resaltadas por Malerba et $\mathrm{a}^{17}$ se da en las técnicas percutáneas, ya que tanto las vías de entrada como los gestos quirúrgicos respetan a las estructuras mencionadas y explican los buenos resultados obtenidos en nuestra serie que mantienen la movilidad en unos parámetros normales en prácticamente el $70 \%$ de los casos intervenidos.

El análisis de nuestros resultados clínicos pone de manifiesto: a) la desaparición del dolor en el $75 \%$ de los casos de una manera absoluta, persistiendo en el $25 \%$ restante leves molestias en los cambios estacionales, o tras la actividad prolongada en bipedestación; b) la desaparición en el $100 \%$ de la serie, de la bursitis sobre la exóstosis del primer metatarsiano, y c) la utilización de un calzado normal o muy levemente modificado en el $99 \%$ de los casos intervenidos. Estos resultados nos hacen pensar, junto a Magnan et $\mathrm{al}^{8}$ que con el paso del tiempo y la difusión de las técnicas percutáneas, éstas se transformarán en técnicas de obligada utilización, al obtener excelentes resultados (superponibles a la cirugía tradicional) habiendo disminuido los riesgos derivados de la vía quirúrgica, de la exposición articular, de la fibrosis secundaria a la cicatrización de la cápsula medial, de las tenotomías y de la capsulotomía lateral, a la vez que mejoran el tiempo de recuperación del postoperatorio inmediato y a medio plazo.

Por lo que se refiere a los resultados radiológicos, los parámetros que debemos corregir en el tratamiento quirúrgico del hallux valgus son numerosos: PASA, ángulo IM, ángulo MF, luxación de los sesamoideos, etc. Siendo imposible conseguir con un gesto único la corrección de todos ellos, en el momento actual, todas las técnicas propuestas por los diferentes autores llevan asociados diferentes gestos que nos hacen obtener resultados mucho más satisfactorios.

Las osteotomías del primer radio han conocido en los últimos años un desarrollo muy importante, habiendo rele- 
gado a las técnicas de artroplastia por resección a un segundo plano, estando sólo indicadas en aquellos casos en los que existe una importante artrosis en la articulación metatarsofalángica. Pero como decíamos, ninguna de las osteotomías propuestas puede por sí sola resolver todos los elementos a corregir en el tratamiento quirúrgico del hallux valgus. El primer dilema con el que nos enfrentamos es el de decidir el punto ideal para realizar la osteotomía. Coincidimos con otros autores ${ }^{18-20}$ en destacar la importancia que la corrección del PASA tiene para poder obtener un resultado mantenido en el tiempo, ya que siempre que nosotros solamente modifiquemos la posición de los huesos (falange sobre metatarsiano, al liberar las partes blandas, o metatarsiano sobre falange en las osteotomías basales), no obtendremos una corrección duradera ya que el paso del tiempo y la retracción de las partes blandas producirá la recidiva de la deformidad. Por el contrario, si nosotros modificamos la estructura ósea reorientando las carillas articulares, estaremos consiguiendo restablecer los elementos más sólidos para el mantenimiento de la corrección. Por esta razón defendemos la práctica de osteotomías a nivel distal ${ }^{6,21}$ ${ }^{25}$ con extracción de cuña interna, que son las únicas (junto a las osteotomías en scarff) que nos permiten tener una influencia directa sobre la corrección del PASA, evitando así las recidivas.

La corrección del ángulo IM es otro de los parámetros que debemos corregir en el tratamiento del hallux valgus. Sobre todo ha sido defendido este criterio por aquellos autores que consideran como factor etiopatogénico fundamental la presencia de deformidad en la base del primer metatarsiano, y por tanto consideran prioritaria su corrección. Es evidente que las osteotomías basales ${ }^{26-28}$ nos permiten, de un modo muy eficaz, la corrección del ángulo intermetatarsal, por lo que estas técnicas han sido muy difundidas en los últimos años, utilizadas junto a técnicas de liberación lateral de las partes blandas. Se han recomendado fundamentalmente en aquellos casos en los que existe la presencia de un primer metatarsiano corto, que podría ser aún más acortado tras la realización de osteotomías distales.

Las osteotomías distales, siempre que se practiquen de un modo completo y podamos realizar un desplazamiento lateral del fragmento distal, pueden también conseguir una disminución del ángulo IM de aproximadamente $1^{\circ}$ por cada milímetro de desplazamiento y, por ello, si el primer metatarsiano es lo suficientemente largo, podrán ser recomendadas en aquellos casos en los que se tenga que corregir un ángulo intermetatarsal moderado. Esto coincide con los datos aportados por Jahss et $\mathrm{al}^{29,30}$, que estimaron que las osteotomías distales del primer metatarsiano sólo pueden alcanzar una corrección de $5^{\circ}$ del ángulo IM. Markbreiter y Thompson $^{23}$, tras un estudio comparativo de estos dos tipos de osteotomías (proximales o distales) llegaron a la conclusión de que no tienen ninguna diferencia significativa para la corrección del ángulo IM si éste no es muy elevado.
Nosotros coincidimos con Mann et $\mathrm{al}^{27}$ y Cedell y Astrom ${ }^{31}$, que recomiendan las osteotomías proximales para aquellos casos en los que el ángulo IM está muy aumentado.

En nuestra práctica solamente la aplicaremos, como defiende Schnepp ${ }^{32}$, cuando comprobemos que una osteotomía distal no nos ha dado la corrección necesaria del mismo, y por tanto realizamos la osteotomía bipolar (distal y proximal) que haremos por técnicas percutáneas ${ }^{33}$ obteniendo resultados muy satisfactorios. La corrección obtenida sobre el ángulo metatarsofalángico con la práctica de osteotomías distales del primer metatarsiano es limitada, aproximadamente entre 10 a $25^{\circ}$ según las series ${ }^{34,35}$; por esta razón, diversos autores ${ }^{6,25,36-38}$ recomiendan asociar la liberación de la cápsula lateral y desinserción del abductor a nivel de la falange, con lo que se consiguen correcciones muy superiores a $\operatorname{los} 25^{\circ}$.

Otros autores ${ }^{39-42}$ advierten del aumento de necrosis vascular de la cabeza metatarsiana tras osteotomías distales y liberación de partes blandas, que puede llegar al $40 \%$ de los casos operados. Estos datos están en absoluta discordancia con los aportados por otros autores ${ }^{6,38}$ en los que no se aprecia aumento de necrosis vascular de la cabeza metatarsiana tras osteotomía con liberación lateral de partes blandas. Esto nos hace pensar que esos resultados tan negativos están directamente relacionados con la vía de abordaje que los autores precedentes utilizaban, y que si la realizamos de una manera adecuada, como proponen Jones et $\mathrm{al}^{43}$, los resultados son totalmente superponibles a las series en las que no se hace liberación de las partes blandas.

La falta de corrección del ángulo MF es una de las causas más frecuentes de insatisfacción tras la cirugía del hallux valgus, por ello, si tras la realización de una osteotomía distal más una liberación lateral de las partes blandas persiste un ángulo IM aumentado y su ángulo articular de la base de la falange o DASA (distal articular sect angle) está alterado siendo mayor de $6^{\circ}$, se ha propuesto la realización de una osteotomía de la falange proximal del primer dedo a nivel de su base, tipo Akin, con lo que se mejorarán los resultados de un modo significativo, como demuestran Mitchell y Baxter ${ }^{44}$ y Tollison y Baxter ${ }^{15}$ en sus series. Nosotros hemos introducido la práctica de esta osteotomía de Akin de un modo sistemático en nuestra técnica, ya que no supone un gesto quirúrgico que prolonga el tiempo de la intervención de un modo significativo, ni afecta a la vascularización del primer dedo, como hemos comprobado en nuestras preparaciones anatómicas, y sí que, por el contrario, nos proporciona un mejor resultado con respecto a la corrección del ángulo MF, el DASA, y reequilibra la función de los tendones flexores y extensores en el primer dedo.

En resumen, podemos afirmar que al asociar gestos quirúrgicos, como la osteotomía distal del primer metatarsiano, la liberación lateral de las partes blandas y la osteotomía de Akin en la base de la falange, obtendremos resultados muy satisfactorios, coincidiendo con otros autores ${ }^{9,15,45}$ que se in- 
clinan por la misma práctica de tratamiento.

Con respecto a las complicaciones, puede sorprender, tras el análisis de nuestros resultados, que defendamos la no utilización de síntesis para estabilizar las osteotomías, ya que presentamos un $42 \%$ de movilización de las mismas. Este hecho merece un análisis más profundo; hemos de destacar que de estos 27 casos $(42 \%)$, solamente $5(8 \%)$ sufre un desplazamiento mayor de $2 \mathrm{~mm}$ y solamente $4(6 \%)$ van a tener repercusión sobre el resultado final. De estos 4, 2 de ellos han perdido la corrección obtenida inicialmente del PASA, por lo que pensamos que con el paso de los meses se perderá la corrección obtenida; los otros 2 casos han producido un acortamiento excesivo del primer metatarsiano, siendo la causa de una metatarsalgia por transferencia evidente, que en un caso ha llegado a producir una factura por estrés del segundo metatarsiano, con lo que se resolvió el problema de la metatarsalgia. El quinto caso sufrió un desplazamiento lateral importante, que no condicionó alteración en ningún parámetro de su resultado global, solamente se pudieron apreciar modificaciones radiológicas por un callo hipertrófico sin ninguna repercusión clínica. El resto de los casos incluidos en el grupo de movilización de la osteotomía (22 casos; el 34\% de la casuística) ha sufrido mínimos desplazamientos, sin tener ninguna repercusión sobre los resultados finales, como por otra parte sucede en otras series publicadas ${ }^{46-48}$. No queremos dejar de destacar en este punto que de los 5 casos de movilización significativa de la osteotomía, 4 de ellos pertenecen a los 15 primeros casos intervenidos por nosotros con técnicas percutáneas, y que por tanto encontramos una relación directa de su aparición con el proceso de aprendizaje de la técnica, no habiendo hallado una incidencia similar en los casos intervenidos posteriormente. Por todo ello, coincidimos con Austin y Leventen $^{49}$ en que no es necesario realizar técnicas de síntesis para los fragmentos osteotomizados.

$\mathrm{El}$ acortamiento producido sobre el primer metatarsiano tras la práctica de las osteotomías distales es una consecuencia ineludible ${ }^{50-51}$, sobre todo cuando nos vemos obligados a obtener cuñas internas de determinada entidad para corregir el PASA. Ha sido éste un motivo constante de preocupación, ya que el acortamiento puede conducir a la aparición de metatarsalgia por transferencia si alcanza una magnitud suficiente ${ }^{36,52}$. Las técnicas percutáneas, independientemente del acortamiento producido por la extracción de la cuña, producen un acortamiento complementario de 2 milímetros ocasionado por la línea de corte con fresas giratorias; por todo ello, hemos tenido un acortamiento medio de 7 milímetros en nuestra serie, que coincide exactamente con el que presenta la casuística de Merkel et $\mathrm{al}^{37}$.

Cuando el acortamiento supera los 10 milímetros, aumentará de un modo significativo la presencia de metatarsalgias, como ponen de manifiesto numerosos autores ${ }^{39,53,54}$. Con el objeto de minimizar la aparición de metatarsalgias por transferencia, Mitchell ${ }^{55} \mathrm{y} \mathrm{Wu}^{13}$ proponen descender la cabeza del metatarsiano a la vez que se acorta, obteniendo así una mejor distribución de las presiones sobre la planta del pie. Es importante destacar en este punto un aspecto interesante del diseño de la osteotomía propuesta por Isham, y que nosotros utilizamos como tratamiento del hallux valgus y presentamos en esta serie: el trazo de la osteotomía es oblicuo de arriba abajo (en unos $45^{\circ}$, aproximadamente) y de distal dorsal a plantar proximal. Esta posición de la línea de osteotomía tiene dos consecuencias: la línea de osteotomía se opone al desplazamiento dorsal del fragmento distal de la misma, no permitiendo desplazamientos significativos en esta dirección, y en segundo lugar, la presión de la carga en la deambulación desplazaría hacia atrás el fragmento distal, que se ve empujado a la misma vez en dirección plantar por la superficie proximal del corte de la osteotomía, produciendo así un descenso de la cabeza del metatarsiano que disminuirá las consecuencias de metatarsalgias que podrán producirse por el acortamiento.

Dos han sido las fracturas por estrés que se han producido en nuestra serie, una de ellas, que ya hemos analizado, se produjo tras un desplazamiento excesivo de la osteotomía de Isham, que condicionó un acortamiento y metatarsalgia secundaria; el otro caso se produjo al existir, previamente al tratamiento quirúrgico, una fórmula metatarsal index minus muy acusada, aumentándose en el postoperatorio esta situación por el mayor acortamiento del primer metatarsiano, produciendo metatarsalgia bajo la cabeza del segundo y su posterior fractura por sobrecarga. Este hecho nos ha llevado a ser mucho más agresivos a la hora de plantearnos el tratamiento quirúrgico del hallux valgus, y coincidimos con Barouk $^{56-57}$ y el resto del grupo francés de Pied Innovation, formado por Augollard, Penichon, Maestro, Peirot, Ragusa y Valtin, que defienden el tratamiento del hallux valgus, enfocado como un problema global del antepié (síndrome de insuficiencia del primer radio de Viladot) y no como un problema aislado de la articulación metatarsofalángica del primer radio, debiendo por ello aplicarse simultáneamente todos aquellos gestos quirúrgicos necesarios para corregir de un lado la deformidad del primer radio y de otro tanto las deformidades existentes en los dedos menores o metatarsianos, como los que se podrían producir secundariamente a nuestra actuación sobre el primer radio.

El resto de las complicaciones no merece ningún tipo de comentario especial, ya que el único caso de flebitis presentado se ha dado en una paciente con antecedentes de patología vascular en ese miembro inferior, y se produjo a pesar de haber sido administrada medicación profiláctica (heparina de bajo peso molecular, por vía subcutánea). Las dos roturas de fresas de corte durante el acto operatorio no supusieron alargamiento significativo del tiempo de cirugía ni otro tipo de complicación, ya que se pudieron extraer con suma facilidad con la utilización del fluoroscopio. La ausencia de infección la atribuimos al exquisito cumplimiento de las normas de asepsia utilizadas, al igual que en toda ci- 
rugía del aparato locomotor, y las alteraciones secundarias en la sensibilidad en el primer dedo no han supuesto un problema ni por su magnitud, ni por el número de ellas presentado en nuestra casuística.

En resumen podríamos decir que la técnica de Reverdin - Isham por vía percutánea aplicada al tratamiento quirúrgico del hallux valgus se ha mostrado como un método muy eficaz, proporcionando un $90 \%$ de buenos y muy buenos resultados, según la valoración del paciente, y el $80 \%$ de buenos y muy buenos según la valoración del cirujano. Las técnicas percutáneas para el tratamiento quirúrgico del hallux valgus, correctamente practicadas, permiten obtener buenos resultados sin lesionar los elementos neurovasculares de la zona intervenida, y produciendo daños mínimos sobre los tejidos vecinos. Las complicaciones más temibles de la cirugía, mediante osteotomía por técnicas tradicionales (abiertas) (necrosis avascular de la cabeza del primer metatarsiano, pseudoartrosis de la osteotomía, rigidez articular postquirúrgica e infección) no se han producido en las técnicas de cirugía percutánea de nuestra serie. El desplazamiento o migración secundaria no deseado de la cabeza metatarsal ha sido la complicación más frecuente, que se presentó en el $42 \%$ de los pacientes, pero hemos de destacar que solamente en 6 casos ( $8 \%$ de ellos) alcanzó valores significativos, y sólo 1 caso de éstos tuvo una repercusión negativa sobre el resultado final. El acortamiento del primer metatarsiano y la secundaria metatarsalgia por transferencia a los metatarsianos menores, presente en el $25 \%$ de los casos, ha sido la complicación con mayor repercusión clínica de todas los presentes, y exigirá, en la mayor parte de los pacientes, un tratamiento quirúrgico secundario para resolver este problema. Por ello, coincidimos con Barouk et al en afrontar en un mismo tiempo quirúrgico todas las deformidades existentes en el síndrome de insuficiencia del primer radio por hallux valgus, así como las repercusiones que podamos prever como secundarias en nuestra actitud quirúrgica.

La menor agresión a los tejidos vecinos en el campo quirúrgico, así como el respeto a las estructuras vasculares y nerviosas, hace que se produzca menos reacción inflamatoria, menos edema postoperatorio, menos dolor, y por ello, un mayor confort, una menor invalidez y una deambulación mucho más precoz, eliminando riesgos como la tromboflebitis de los miembros inferiores, la atrofia de Sudek postinmovilización, y mejorando global y significativamente la morbilidad en el postoperatorio.

\section{BIBLIOGRAFÍA}

1. Akin OF. The treatment of hallux valgus-a new operative procedure and its results. Med Sentinal 1925;33:678-83.

2. Groulier PL, Curvale G, Prudent HP, Vedel F. Resultats du traitement de l'hallux valgus selon la technique de McBride «modifiee» avec ou sans osteotomie phalangienne ou meta- tarsienne complementaire. Rev Chir Orthop 1988;74:539-46.

3. Andreasi A, Coppo M. L'intervento di Reverdin-Gren modificato nel trattamento quirurgico dell'alluce abdotto-valgo. En: Gaggi A, editor. Progresi in Medicina e Chirurgia del Piede. L'alluce valgo. Bologna: Aulo Gaggi, 1997; p.105-14.

4. Grace D, Hughes J, Klenerman L. A comparation of Wilson and Hohmann osteotomies in the treatment of hallux valgus. $\mathrm{J}$ Bone Joint Surg Br 1988;70B:236-41.

5. Klosok JK, Pring DJ, Jessop JH, Maffulli N. Chevron or Wilson metatarsal osteotomy for hallux valgus. A prospective randomised trial. J Bone Joint Surg Br 1993;75B:825-9.

6. Petje G, Steinbock G, Schiller C. Radiographic analysis of metatarsus primus varus. 45 feet followed 15 months after distal metatarsal osteotomy and lateral soft-tissue release. Acta Orthop Scand 1997;68:567-70.

7. Wilson JN. Oblique displacement osteotomy for hallux valgus. J Bone Joint Surg Br 1963;45B:552-6.

8. Magnan B, Montanari M, Bragantini A, Fieschi S, Bartolozzi P. Trattamento chirurgico dell'alluce valgo con tecnica «mini-invasiva» percutanea. En: Gaggi A, editor. Progresi in Medicina e Chirurgia del Piede. L'alluce valgo. Bologna: Aulo Gaggi, 1997; p.91-104.

9. Coughlin MJ. Hallux valgus. Instr Course Lect 1997;46:357-91.

10. Funk FJ Jr, Wells RE. Bunionectomy with distal osteotomy. Clin Orthop 1972;85:71-4.

11. McClamry E. Thecniques in forefoot reconstruction. J Am Podiatric Med Assoc 1975;65:588-99.

12. Wu K. Mitchell: An analysis of 430 personal cases plus a review of the literature. J Foot Surg 1987;26:277-81.

13. Wu K. Modified Mitchell's bunionectomy (Wu's bunionectomy). Orthopedics 1997;20:253-7.

14. Giannini S, Ceccarelli F, Mosca M, Montanari P. Algoritmo nel trattamento chirurgico dell'alluce valgo. En: Gaggi A, editor. Progresi in Medicina e Chirurgia del Piede. L'alluce valgo. Bologna: Aulo Gaggi, 1997; p.155-66.

15. Tollison ME, Baxter DE. Combination chevron plus Akin osteotomy for hallux valgus: should age be a limiting factor? Foot Ankle 1997;18:477-81.

16. Laughin T. Complications of distal first metatarsal osteotomie. J Foot Ankle Surg 1996;34:524-31.

17. Malerba F, De Marchi F, Hosscinazadeh M. L'osteotomia di Austin per la correzione dell'angolo intermetatarsale in pazenti con alluce valgo. En: Gaggi A, editor. Progresi in Medicina e Chirurgia del Piede. L'alluce valgo. Bologna: Aulo Gaggi, 1997. p.79-90.

18. Isham $\mathrm{S}$. The Reverdin-Isham procedure for the correction of hallux abducto valgus - A distal metatarsal osteotomy procedure. Clin Podiatr Med Sur 1991;8:81-94.

19. Mann RA, Coughlin MJ. Hallux valgus: etiology, anatomy, treatment and surgical considerations. Clin Orthop 1981;157: 31-41.

20. Coughlin MJ. Hallux valgus in men: effect of the distal metatarsal articular angle on hallux valgus correction. Foot Ankle 1997; 18:463-70.

21. Donnelly RE, Saltzman CL, Kile TA, Johnson KA. Modified chevron osteotomy for hallux valgus. Foot Ankle 1994;15: 642-5.

22. Easley ME, Kiebzak GM, Davis WH, Anderson RB. Prospective, randomized comparison of proximal crescentic and proximal chevron osteotomies for correction of hallux valgus deformity. Foot Ankle 1996;17:307-16.

23. Markbreiter LA, Thompson FM. Proximal metatarsal osteotomy in hallux valgus correction: a comparison of crescentic and chevron procedures. Foot Ankle 1997;18:71-6.

24. Tango A, Poladas G. Trattamento chirurgico dell'alluce val- 
go: osteotomia scarf e gesti associati. En Gaggi A, editor. Progresi in Medicina e Chirurgia del Piede. L'alluce valgo. Bologna: Aulo Gaggi, 1997; p.71-8.

25. Tranka HJ, Zembsch A, Wiesauer H, Hungerford M, Salzer M, Ritschl P. Modified Austin procedure for correction of hallux valgus. Foot Ankle 1997;18:119-27.

26. Coughlin MJ. Proximal first metatarsal osteotomy. En: Johnson KA, editor. The Foot and Ankle. Master Techniques in Orthopaedic Surgery. New York: Raven Press, 1994; p. 85-105.

27. Mann RA, Rudicel S, Graves SC. Repair of hallux valgus with a distal soft-tissue procedure and proximal metatarsal osteotomy. A long-term follow-up. J Bone Joint Surg Am 1977;74A:124-9.

28. Thordarson DB, Leventen EO. Hallux valgus correction with proximal metatarsal osteotomy: two year follow-up. Foot Ankle 1992;13:321-6.

29. Jahss MH, Troy AI, Kummer F. Roentgenographic and mathematical analysis of first metatarsal osteotomies for metatarsus primus varus: a comparative study. Foot Ankle 1985;5: 280-321.

30. Jahss MH. Hallux valgus: further considerations of the first metatarsal head [editorial]. Foot Ankle 1981;2:1-4.

31. Cedell CA, Astrom M. Proximal metatarsal osteotomy in hallux valgus. Acta Orthop Scand 1982;53:1013-8.

32. Schnepp J. Traitement de l'hallux valgus avec metatarsus varus irréductible du premier métatarsien. L'ostéotomie métatarsienne bipolaire. Rev Chir Orthop 1983;Suppl II:69.

33. Toepp C, Salcedo M. Closing base wedge osteotomy. Clin Podiatr Med Surg 1991;8:137-51.

34. Blum JL. The modified Mitchell osteotomy-bunionectomy: indications and technical considerations. Foot Ankle 1994;15: 103-6.

35. Briggs TWR, Smith P, McAuliffe TB. Mitchell's osteotomy using internal fixation and early mobilisation. J Bone Joint Surg Br 1992;74B:137-9.

36. Kitaoka HB, Patzer GL. Salvage treatment of failed hallux valgus operations with proximal first metatarsal osteotomy and distal soft-tissue reconstruction. Foot Ankle 1998;19: 127-31.

37. Merkel KD, Katoh Y, Johnson EW, Chao EYS. Mitchell osteotomy for hallux valgus: long-term follow-up and gait analysis. Foot Ankle 1983;3:189-96.

38. Pochatko DJ, Schlehr FJ, Murphey MD, Hamilton JJ. Distal chevron osteotomy with lateral release for treatment of hallux valgus deformity. Foot Ankle 1994;15:457-61.

39. Carr CR, Boyd BM. Correctional osteotomy for metatarsus primus varus and hallux valgus. J Bone Joint Surg Am 1968; 50A:1353-67.

40. Hattrup SJ, Johnson KA. Chevron osteotomy: analysis of factors in patients dissatisfaction. Foot Ankle 1985;5:327-32.
41. Meier PJ, Kenzora JE. The risks and benefits of distal first metatarsal osteotomies. Foot Ankle 1985;6:7-17.

42. Shereff MJ, Yang QM, Kummer FJ. Extraosseus and intraosseus arterial supply to the first metatarsal and metatarsophalangeal joint. Foot Ankle 1987;8:81-93.

43. Jones KJ, Feiwell LA, Freedman EL, Cracchiolo A. The effect of chevron osteotomy with lateral capsular release on the blood supply to the first metatarsal head. J Bone Joint Surg Am 1995;77A:197-204.

44. Mitchell LA, Baxter DF. The chevron-Akin double osteotomy for correction of hallux valgus. Foot Ankle 1991;12:7-14.

45. Armaneck DL, Juda EJ, Oloff LM. Opening base wedge osteotomy of the first metatarsal utilizing rigid external fixation. J Foot Surg 1986;25:321.

46. Crosby LA, Bozarth GR. Fixation comparison for chevron osteotomies. Foot Ankle 1998;19:41-3.

47. Feit EM, Scherer P, De Yoe B, Gerbert J, Patel V. The nonfixated Austin bunionectomy: a retrospective study of one hundred procedures. J Foot Surg 1997;36:347-52.

48. Hyytinen T, Lantto E, Kallio P, Salo S, Kaukonen JP. Modified distal metatarsal osteotomy for hallux valgus. Ann Chir Gynaecol 1995;84:81-4.

49. Austin DW, Leventen EO. A new osteotomy for hallux valgus: a horizontally direct «V» displacement osteotomy of the metatarsal head for hallux valgus and primus varus. Clin Orthop 1981;157:25-30.

50. Banks AS, Cargill RS, Carter S, Ruch JA. Shortening of the first metatarsal following closing base wedge osteotomy. J Am Podiatr Med Assoc 1997;87:199-208.

51. Christensen PH, Hansen TB. Hallux valgus correction using a modified Hohmann technique. Foot Ankle 1995;16: 177-80.

52. Lapidus PW. The author's bunion operation from 1931 to 1959. Clin Orthop 1960;16:119.

53. Hawkins FB, Mitchell CL, Hedrick DW. Correction of hallux valgus by metatarsal osteotomy. J Bone Joint Surg Am 1945; 27A:387-94.

54. Miller JW. Distal first metatarsal displacement osteotomy. Its place in the schema of bunion surgery. J Bone Joint Surg Am 1974;56A:923-31.

55. Mitchell CL, Fleming JL, Allen R, et al. Osteotomy-bunionectomy for hallux valgus. J Bone Joint Surg Am 1958; 40A: 41.

56. Barouk LS. Notre expérience de l'ostéotomie «Scarf» des premier et cinquième métatarsiens. Med Chir Pied 1992;8: 67-84.

57. Barouk LS. Nouvelles ostéotomies de l'avant-pied. Description. Insertion dans un concept thérapeutique global. Cahier d'Enseignement de la SOFCOT 1996;54:55-84. 